\title{
Flood Impacts in Oshana Region, Namibia: A Case Study of Cuvelai River Basin
}

\author{
Anna -Marie Niipare ${ }^{1}$, Andries Jordaan ${ }^{2} \&$ Nguza Siyambango $^{3}$ \\ ${ }^{1}$ City of Windhoek, Division of Emergency and Disaster Risk Management, Windhoek, Namibia \\ ${ }^{2}$ Disaster Management Training and Education Centre for Africa (DiMTEC), Faculty Natural and Agricultural \\ Sciences / Natuur- en Landbouwetenskappe, Bloemfontein, Republic of South Africa / Republiek van Suid-Afrika \\ ${ }^{3}$ University of Namibia, Multidisciplinary Research Centre, Life Sciences Division, Windhoek, Namibia \\ Correspondence: N. Siyambango, University of Namibia, Multidisciplinary Research Centre, Life Sciences \\ Division, Private Bag 13301, Windhoek, Namibia. E-mail: nsiyambango@unam.na; nguzasiya@gmail.com
}

Received: November 22, 2019

Accepted: January 31, $2020 \quad$ Online Published: March 30, 2020

doi:10.5539/jgg.v12n1p8

URL: http://dx.doi.org/10.5539/jgg.v12n1p8

\begin{abstract}
Floods are among the global natural disasters that are known to have major negative societal effects. The extent of floods can determine the degree of impact to be made. Floods can cause extensive economic losses, consequently affecting livelihoods, businesses, infrastructures and basic services. This study investigated the impact of floods in communities within the Oshana Region in the northern areas of Namibia. Primary and secondary data were collected in efforts to understand the impact of floods, and the causes of vulnerability to such events. Loss of field crops, destruction of houses, destruction of roads and other infrastructure, and loss of human lives were the major flood impacts that have been identified. The study findings revealed that vulnerability to floods is mainly due to lack of resources, poverty, poor infrastructure, limited budget, inactive disaster risk management structures in the region, rapid population change, non-existing Early Warning System (EWS), lack of awareness of the flood impacts, low income, and the fact that many houses are headed by females. In the absence of coping strategies, communities mainly depend on external relief, particularly for temporary shelter and provision of basic needs. It was concluded that the ability of communities and individuals to cope with flood impacts is related to their culture, history, knowledge system, power dynamics and governance. A further conclusion was that, the vulnerability of communities in the Oshana Region resulted in reduced household resilience to flood disasters.

The study recommended a further investigation into other flood prone regions in Namibia. Other notable recommendations included:

- the availing of information on climate variability and best coping strategies in flood prone communities,

- flood hazards awareness,

- developing and implementing mitigation measures for flood disasters,

- development of a policy on the construction of houses in efforts to avoid flood risks,

- and the development of information communication channels for EWS.
\end{abstract}

Keywords: Flood Impacts, Vulnerability, Natural Disasters, Oshana Region

\section{Introduction}

Disasters have devastating impacts on countries and affect almost all the nations. Among others, disasters such as earthquakes, famines, epidemics, violent conflicts, diseases and hunger can be lethal, and may shorten people's lives (Wisner, 2003). Depending on their magnitude, disasters can cause serious disruption of community and societal functions, further resulting in widespread human, material, economic or environmental losses to the point of making it difficult for the affected communities to cope with their little resources. Natural disasters occur when natural hazards such as volcanic eruption, floods, and earthquakes affect human vulnerability, caused by the lack of proper emergency management, financial constraints and environmental impact. The extents of their impact depends on the population of a given area, which need to be supported and resist the disaster (Zaman, 1991). Apart from natural disasters, there are other disasters that are human-induced, caused by human actions or involving the failure of a system, called man-made disasters (Smith, 2006). 
The need to understand natural disasters such as floods, resulted in the pursuit of this study. This study aimed to establish an understanding of the impact of floods in the northern central Namibia, particularly the Oshana region. The study investigated the flood preparedness, awareness and coping capacities of the community around the Cuvelai River basin.

\subsection{Theoretical Framework}

The theoretical framework presented in this paper clarifies the general management of floods. It presents the progression of vulnerability of the Oshana Region. Generally, floods are disasters that occur naturally, however, they can also be attributed to political, social and economic factors, depending on the situation or area where they are occurring (Wisner et al., 2003). Unfortunately, there are currently a lack of, or limited measures in place to prepare, mitigate and effectively reduce flood impact this results in extensive destruction (Smith, 1998).

Guided by international best practices, the newly-formed Disaster Risk Management function comprises of response, recovery, prevention and mitigation efforts as part of methods aimed at limiting or preparing the possible impact of disaster incidents (Mandelametro, 2008). This process is also known as the Disaster Management continuum, which is traditionally used to explain disaster risk management, dividing the functions into pre- and post-disaster phases.

The post-disaster phase includes the disaster event itself, which prompts response and recovery functions, followed by rehabilitation of the affected areas, structures and livelihoods in an attempt to return the affected community to its original or improved pre-disaster state. The pre-disaster phase comprises of preparedness, mitigation and prevention strategies that incorporate planning and development processes aimed at mitigating the potential impact of a disaster and to prevent such an event from occurring in future. Preparedness in general strengthens the community's resilience through capacity building, inventiveness, this allows the community to cope better with the disaster and recover much quicker. As a form of preparedness, early warning systems are put in place as a mechanism for communities to act before disasters hit them hard. On the contrary, some communities tend to focus on post-disaster risk reduction, which makes them vulnerable to floods. A tendency to put up impact reduction strategies only worsen their vulnerability to disasters.

To identify the root causes of flooding in the Oshana Region and the dynamic pressures which existed before people decided to settle in unsafe and vulnerable areas, this research used the Pressure and Release PAR Model that was advocated by Blaikie et al. (1994) and modified by Wisner et al. (2003). The model was used to analyze the Progression of Vulnerability and Progression of Safety for the Oshana Region; to identify the connection between the risks being observed in the region; and to figure out the cause of community vulnerability to flooding. The years of flood occurrence that were of particular interest are: 2004, 2008, 2009, 2010 and 2011 (UNICEF, 2012).

This study used Oshana Region as a case study for the following reasons: i) Oshana has been one of the most affected regions in the past by floods; ii) The region hosts Oshakati Town, which is regarded as the major town that is promoting economic development in northern Namibia; iii) The region has good road infrastructure, which enabled the researcher to commute and conduct the research without transport challenges; iv) Most people in the Oshana Region speak Oshiwambo, and the researcher is well conversant in the same language, which made communication easy to collect raw data without the need for translation; and v) Finally, the inhabitants of the region rely on subsistence farming, with farmers growing pearl millet, sorghum and keeping small herds of cattle and goats which are said to be vulnerable to floods.

The overall objective of this research was to establish mitigation measures for flood impacts in the Oshana region, focusing more on the early warning system (EWS) and on strengthening the coping capacities for the region. The specific objectives were to: i) analyse the processes that are undertaken to mitigate the impact of floods in the Oshana Region; ii) identify the challenges faced in the process of managing floods in the Oshana Region; and iii) propose useful recommendations that could potentially reduce the impact of the Cuvelai River Basin/Oshana regional floods in future.

In addition to the objectives the research addressed the following questions: i) What negative impact did previous floods have on the community? ii) Is the community aware of the risk that is being posed by the Cuvelai River Basin? iii) What leads the floods to become disastrous?

\subsection{Importance of the Problem}

The Oshana community is exposed to flooding on an annual basis since 2004. People flee their homes when it floods but still go back to their homes when the water drains. Because of the flooding, commercial and industrial activities are disrupted, local access to health facilities and schools being cut off, urban sewage systems 
overflowing with the inundation of water supply and sewage stations (National Planning Commission, 2009). Most people in the Oshana region live in rural areas, with their income highly depending on subsistence farming. Many farmers lose the majority of their annual harvest as well as their livestock, jeopardizing their income and food sources. Many rural residents, as well as urban dwellers, lose their homes to the floods, in some cases houses made of mud simply washed away by the floods (National Planning Commission, 2009).

Most of the reported deaths occurred late in the night or in the early hours of the morning when victims walked back home through the flooded iishana and drowned, in addition a few people drowned in the attempts to paddle on safer grounds by the use of hurriedly made canoes (Oshana Regional Council, 2009).

Floodwater became a hazard for learners who have to cross-streams and floodplains to get to schools. More than 21 drowning cases of schoolchildren have been reported in 2009 (Oshana regional council, 2009).

\subsection{Relevant Scholarship}

\subsubsection{Impacts of Flooding in the Africa}

Flood disasters are the most frequent and devastating natural disasters in the African region, and like disasters in general, their impacts have grown in spite of our improved ability to monitor and describe them (White et al, 2001). For the past decades, the number of flood disasters has increased compared to other forms of disasters (Dutta \& Herath, 2005).

According to Action Aid International (2016), the unpredictability of rainfall is shown both by observations such as the large fluctuations in the levels of Lake Victoria in Africa since 1980, and by the experiences of long-term urban slum residents, who report much more frequent storms producing floods since 1990.

Heavy floods have severely affected the southern African region in 2010. Three particular countries namely Lesotho, Namibia and South Africa, have faced severe damage and loss of lives due to these extreme conditions (FAO, 2010). More than 26 people were reported dead over the first two months of 2010 in Lesotho, and over 5,000 people have been displaced, while 672 houses were destroyed, furthermore the situation worsened as the rain continued which resulted in major destruction to the livelihoods as their crops were destroyed by the flood (FAO, 2010).

According to the United Nations (2009), South Africa's 33 districts and municipalities in eight of the nine provinces were affected by floods. More than 91 people died and 20,000 had been affected (United Nations, 2009). The KwaZulu-Natal province was the worst affected. In urban areas, such as major parts of Gauteng, (flash) floods particularly affected informal settlements (United Nations, 2009). It further reported that families had to be relocated by national authorities and post-disaster activities in Gauteng, which included urgent repair of the roads and storm-water drainage systems.

In the Northern Cape Province, large commercial agricultural areas had been damaged in 2010. The estimated cost for the farming sector around the country is about 2.8 billion rand ( $\$ 392$ million) in damages (United Nations, 2009).

January and February 2011, flooding in eight of South Africa's nine provinces led to the deaths of more than 100 people, damaged thousands of homes and interrupted export operations in the mining and agricultural industries. Preliminary assessments have shown that approximately one million acres of agricultural land have been affected, particularly on those farms situated in close proximity to the major Vaal and Orange River systems and their catchment areas (Dinnie, 2011).

According to Mucavele (2011) during the second week of January 2011 Maputo City experienced heavy rainfalls around $200 \mathrm{~mm}$ in 3-4 sequentially days. This resulted in most areas of Maputo being flooded with impacts on Health and Sanitation of the impoverished neighborhoods of the city. In total, 86 houses where flooded and 107 families were affected (Mucavele, 2011).

The 2000 flooding in Mozambique caused tragic loss of lives and the immediate economic impacts of loss of properties and crops. The floods of 2000 were estimated to have had a significant long term impact on the economy of Mozambique, with some experts suggesting as much as a 25\% reduction in Gross Domestic Product (GDP) as a direct result of the floods (Wareham, 2000).The unpredicted impact in Mozambique was the displacement of unexploded landmines from the civil war (Wareham, 2000). Thousands of landmines were moved by floodwaters. These mines were previously located in areas that were known, mapped and avoided, but once the flood waters receded, many were moved to new locations, posing a significant threat to the local people (Wareham, 2000).

The severity of the 2010 floods devastated the top soil of large portions of agricultural land in the lower Limpopo River basin (United Nations, 2009). The flood caused a displacement of 500,000 people, damaging housing, 
agricultural infrastructure, public and private buildings, schools, hospitals, water and energy supply systems, roads networks, railways, telecommunications and more than 700 lives lost (United Nations, 2009). It further reported that due to a lack of access to adequate sanitation and drinking water, nearly 800,000 people were put at a high risk of infectious diseases.

USAID (2007) reported that heavy rainfall on January 22, 2007 caused extensive flooding in Angola's Luanda, Bengo, Huambo, Lunda Norte, and Benguela municipalities, killing more than 70 people, destroying homes, and displacing thousands of people. A number of roads have been cut off and some villages and towns were only accessible by boat (USAID, 2007).

The Angolan 2007 flooding had a huge impact on the country's economy (USAID, 2007). The country needed aid from the international organization to manage the flood (USAID, 2007). Red Cross stated that about 25,000 people have lost their homes in southern Angola, flooding caused by three weeks of non-stop heavy rain (USAID, 2007). About 125,000 people have been affected across Cunene province by the floods (USAID, 2007).

The United Nations (2009) reported that Senegal was hit by floods resulting from several weeks of heavy rainfall that have impacted 264,000 people and the economy of the country as roads, agricultural lands and infrastructures were damaged severely. United Nations (2009) further reported that the disaster affected 317,000 people, 1,000 kilometers of roads were destroyed, 210 schools and 45 health facilities damaged and 630 drinking water facilities devastated or contaminated.

According to Akefu, (2005) flooding is a serious ecological issue affecting Accra, and with rising sea levels, it may become an even greater problem. Floods currently are usually of short duration and are caused by heavy rains that generally occur in June and July. Flood events have been recorded in 1973, 1986, 1995, 1999, 2001, and 2002 (Akefu, 2005). The impacts of flooding range from property damage, the ability of flood waters to spread pollution from solid waste, industrial waste, and sewage is an important health and environmental issue particularly in poor areas (Akefu, 2005).

The consequences of flooding are often disastrous but there can also be beneficial effects of flooding. Thomas, (2009) reported that some of the most fertile land in the world lies alongside rivers, the Nile valley being the one of the example. For thousands of years, the Egyptian people have relied upon the water of the Nile river to overflow their banks every year carrying with them fertile silt that makes agriculture possible. Floods spread sediment containing beneficial nutrients to topsoil that might never arrive there otherwise.

\subsubsection{Impacts of Flooding in Namibia}

The impacts of floods have long been recognized as complex and multifaceted (Wisner et al. 2003). Throughout the last century, flooding has been one of the costliest disasters in terms of both property damage and human casualties (Wisner et al., 2003).

Those tasked with the responsibility of resolving the flood situation in the north central part of Namibia, have acknowledged that finding one and everlasting solution to floods problem proved to be almost impossible (Office of The Prime Minister, 2011).

\subsubsection{Namibian Flood Impacts of 2008}

Oshana regional council (2009) reported that abnormal high levels of rainfall occurred in early 2008 in northern Namibia and southern Angola, which led to a severe flooding across much of northern part of Namibia on a level unseen for four decades. Due to the 2008 flood disaster, there were 57 flood related deaths reported, about 215000 people were affected and more than 63000 domestic livestock were lost. Most people live in rural areas and mostly depend on subsistence farming thus the majority of affected people were communal farmers (Directorate of Emergency Management, 2008).

\subsubsection{Namibian Flood Impacts of 2009}

Since early 2009, torrential rains and severe flooding in the north-central and northeastern regions of Namibia have killed more than 100 people, over 350,000 people have lost their livelihoods, and more than 55,000 have been displaced (Oshana regional council, 2009). The flood of 2009 was reported to be worse than the 2008, which affected large areas in northern and northeastern Namibia including Omusati, Ohangwena, Oshana, Oshikoto, Caprivi and Kavango regions as well as areas in Angola, Botswana, Mozambique and Zambia (Newsham \& Thomas 2009).

The loss of lives, homes, businesses properties, and the damage to crop fields, schools, health and other social facilities prompted the country's President, Hifikepunye Pohamba to declare a state of emergency on 17 March 2009 (Namwater report, 2009). The floodwaters have damaged buildings, homes, schools, health facilities, 
mahangu \& maize fields and infrastructure while displacing at least 300,000 people (United Nations, 2009). Oshana regional council (2009) reported that 2009 flood was a major event, with levels not experienced since the late 1960s. There were floods of comparable magnitudes during the 1960s, which were followed by a period of relative stability during the 1980 s and 1990s. In the mid-2000s, the pattern of heavy flooding started again (Oshana regional council, 2009).

Floods with sometimes-serious impacts occur in Namibia regularly in the four north-central regions as well as further to the east in the regions Kavango and Caprivi (Newsman et al, 2009). ['Impacts of floods in the northern central Namibia are complex. According to Oshana region (2009.8), "More than 200000 people in Namibia were affected by heavy flooding near the northern border of Angola since January 2009". Business mostly SMEs and communication networks such as roads and telecommunications were also severely damaged. More people were displaced and relocated to temporary shelters (Oshana regional council, 2009).

The following gives an overview about most significant impacts of the 2009 disaster, according to the report on the 2009 Flood Disaster Response (OPM-DDM, 2009):

* Over 677,542 people were directly and indirectly affected

* Over 54,581 people were displaced, including up to 16,394 people in relocation camps

* 105 flood related deaths were reported

* 10,393 livestock were lost

* 3,000 cattle were trapped on islands

* 328 schools were affected with about 93,700 learners

* 1,066 Small to Medium Enterprises were closed

* 24,754 farmers had their crop fields damaged

* 53,208 hectares of crop fields were damaged

* $70-80 \%$ loss of crop production in the 2009/10 consumption year

* 3,669 communal farming families lost their grain stocks

* hospitals and 29 clinics, 73 outreach services were cut off

* N\$1.7 billion (1\% of GDP) worth of damage and losses were reported

Due to the fact that the institutional level in rural communities is very weak when it comes to flood disasters, people could hardly adapt to the impacts of flooding (Oshana regional council, 2009). Certainly many of them had for example possibilities to sleep on elevated areas or to store their belongings on safer ground but nearly nobody could rescue crops in the fields or crop storages (Oshana regional council, 2009).

According to the World Health Organization (2009), psychological health impacts that have been recorded after the 2009 in the northern Namibia include acute stress, clinical depression and anxiety. A number of reports have shown that these impacts are made worse by the scale of the flood, the time taken to return to normal, the presence of contaminants, evacuation, and ineffectiveness of other actions and help received.

Floods are often followed by rumors of epidemics such as Cholera or Typhoid. Flooding had a very huge impact on the sewerage system of most towns in the affected regions. In Ondangwa town in the northern Namibia, there were reports of the oxidation ponds, which overflowed in the rain waters causing a serious threat to the communities downstream where this water was used for household purposes in 2009 (Oshana regional council, 2009). Access to clean water was a challenge in most camps as people drew their drinking water from flooded ponds near the camps. Another serious concern was toilets and bathroom facilities, as they were inadequate to support the total population in the camps. This was aggravated by the fact that people were not observing, as the surrounding areas were littered (Ondangwa town council, 2009) When nature calls, people helped themselves in the nearby bushes, which served as a threat to a healthy situation because when it rains the dirt is washed back to the tents (Oshana regional council, 2009).

\subsubsection{Impacts of Flooding in 2010}

The following gives an overview about the flood events of 2010 with a snapshot on the worse flood in 2011. Both flood events had consequential effects in the affected areas including the loss of lives and livestock, displacement of population, destruction of homesteads, crops and the social infrastructure and generally effecting seriously on the livelihoods of the affected populations (Denbosch, 2011). 
Stormy heavy rain was experienced during the night of 14 April 2010 and the early morning of 15 April 2010 in Oshakati and the surrounding areas. Most of the areas were flooded especially Oneshila, Okandjengedi, Oshoopala, Evululuko, Sky and Oshikango location. It also indicated that Oshakati has received $77.8 \mathrm{~mm}$ rain.

The causes of the flood in north-central Namibia were a combination of the above-normal rainfall received in the affected regions and the high inflows in the Cuvelai basin with floodwaters from southern Angola (Spiazzi, 2011). Although there was no accurate documentation of economic impacts of floods, there is evidence that floods have caused structural damages, loss of properties and have resulted in economic and livelihoods losses that have a long-term impact on Namibia's development (Denbosch, 2011).

\section{The 2010 flood situation (Office of the Prime Minister, 2010)}

In 2010, the floods have covered more than 450 square Kilometers affecting the regions of Omusati, Oshana, Ohangwena and Caprivi.

- 65000 People affected

* 44 Primary Schools affected

* 37 Secondary Schools

* 30 Clinics

* 25000 herds of Livestock

* There was Cholera outbreak and 455 cases have been reported two (2) people have died from cholera

* 1599 malaria cases were reported

Some health impacts are a result of floods, which include shock, gastrointestinal illnesses particularly if floodwaters were contaminated with sewage, and respiratory illnesses (Hajat et al. 2003). In the Namibian situation, there were cases of gastrointestinal effects after the severe flooding in the northern central Namibia in 2009 and 2010.

\subsubsection{Namibia Flood Impacts of 2011}

Abnormal rainfall occurred in March 2011 in the northern Namibia and Southern Angola, which led to flooding across the four-region part of Namibia on a level that has not be seen in centuries (Amupadhi, 2011). The 2011 flood left many uncounted people homeless and it has affected the government, local business people, pupils and the communities. Historically flooding in the Cuvelai basin has been regularly, the 2011 has been the worse in terms of the geographical area affected. More than 100,000 learners were affected, more than 750,000 people livelihoods disrupted in Omusati, Oshana, Ohangwena and Oshikoto region (Amupadhi, 2011).

Oshana region has been badly affected in 2011, in terms of the population, fields, schools, health facilities, roads and business facilities. The region has a population of 161916 . Out of this, number 30602 people were affected. A number of 2927 were displaced; fields affected are 5120 with 27010 ha (Oshana regional council, 2011).

The flood started on 21 January 2011, affected few people in informal settlements and few villages. On 28 February 2011, the water heavily entered informal settlements of Oshoopala, Oneshila, Okandjengedi, Uupindi, Sky and Eemwadi location and most constituencies were also affected. The situation worsened drastically as from the 25 March 2011 when more people were relocated to the high land at Oshoopala and Ekuku Centre in Oshakati and tents were also taken to constituencies to accommodate those people their houses were flooded (Oshana regional council, 2011).

\subsection{Flood Mitigation}

World Bank (2006) recommended that flood early warning and forecasting in most parts of the world could produce information with longer lead-times. It further suggested that early warning and forecasting are useful for both contingency planning and defining immediate actions in responding to a flood. Poor people need early warning most, but many of them do not understand weather forecasting or the language of early warning (World Bank, 2006). Kelman (2001) explained that most people affected by the 1998 floods in England and Wales did not receive a warning, which led to a revision of the Environment Agency's procedures and the establishment of flood line. Hence in 2000 floods in England and Wales did not result in loss of life since warning systems gave authorities more chance to evacuate those at risk (Keith \& Petley, 2009).

In Oshana region the hydrology division within Namibian Ministry of Agriculture Water and Forestry used staggered gauge plates installed in Evale to provide reliable information on the flood situation (Langerhoven, 2008). 
According to Smith (1998), there are a number of non-technical things that can be done to avoid flooding namely: * Community habit, especially concerning waste (solid and liquid) disposal.

* Organization activities to identify the people who are vulnerable to floods such as children, old people, the disabled, and pregnant women.

* Identify the most important things to carry during a flood.

* Community knowledge of flood orientation, and the direction of its occurrence.

* Determine locations safe from flood and work to improve the location.

* Seek help in making buildings flood-resistant.

The fact that flood problems can be solved by non-technical actions will improve the endurance and resistance of the community. The community will then understand that this risk must be taken care of and will be able to determine the action that they will execute. If community resistance is improved, flood mitigation can be minimized and the level of losses will be significantly reduced.

\subsection{Flood Early Warning System}

In Namibia, detection of the likelihood for flooding is achieved by meteorological and hydrological observations (Langerhoven, 2008). Flood warning give time to evacuate people if necessary and to move valuables from buildings and properties. He further explains that flood warning is only useful, if the information about the risk is communicated effectively to the flood warning operator who then will pass on the degree of threat to the public via either radio, television. Therefore, it is important that the early warning system provides valid information to the flood warning operator to enable them to transmit informed judgments to the appropriate agencies and hence to the general public.

\subsection{Hypotheses and Their Correspondence to Research Design}

The key questions that are of central importance to our purpose are as follows: (i) what methods can be identified of mitigating the impacts of flooding in the Oshana region, with greater emphasis on early warning system and strengthening the coping capacity for the region? (ii) what processes are undertaken to mitigate the impacts of the flood in Oshana region? (iii) what are the challenges that are encountered in the process of managing the flood situation in Oshana region? (iv) what useful recommendations can be provided that can contribute to the reduction of flood impact in the Oshana region?

In order to better understand the shortcomings in the attempts made to reduce the impact of the floods, the research has adopted a qualitative research method.

The following validate the selection of a qualitative research design. The research seeks to gain the insight into people's attitudes, behaviors, value system, aspirations, concerns and life styles. Firstly, the research was aimed at finding out how people reacted to early warnings (i.e. do they take it seriously and adhere to the instructions and recommendations or do they ignore it). Secondly, the research attempted to get an in-depth knowledge of why people return to same area after the flood. Thirdly, the research focused on the type of structures used for housing within the area. Fourthly, the research attempted to understand how the community copes with their resources during and after the flood. These are normally achieved by following a qualitative research design.

\section{Method}

The study relied on the use of primary and secondary data. In urban areas, primary data were obtained mainly from the result of interviews with key informants at the community level and also visual observations were used to determine the physical vulnerability of the selected community.

\subsection{Subsections}

Primary data included a questionnaire and interviews. A structured questionnaire was administered to the villagers in addition to oral interviews and on the spot assessment of the respondents' houses to determine the extent of damage to properties. The questionnaire elicited information on the socio-economic characteristics of the respondents, their opinion of government handling of the situation, their coping mechanisms with the disaster incidents as well as their adaptation measures.

The secondary data were sourced from literature on communities from the Oshana Region especially those related to flooding. Relevant officials of the Oshana Regional Council were interviewed as part of the primary data collection process. Most of the officials that were interviewed were from the villages within the regions. Interview was also conducted with some members of the Directorate of Disaster Risk Management. 


\subsection{Participant Characteristics}

Participant profile consisted of individuals from Oshana region who have the relevant first and second-hand information about the flood caused by Cuvelai river basin. In addition, participants include Senior Officials from Oshakati, Ongwediva and Ondangwa town councils, Officials from the hydrology department (Ministry of Agriculture, Oshana region), Oshana regional council Officials.

\subsection{Sampling Procedure}

This study employed a purposive/judgmental sampling, stratified random sampling and snowball sampling method. Welman et al. (2005) perceive judgmental sampling as the most important type of non-probability sampling. The researcher being originally from the Oshana Region, used her experience to select participants that to her discretion are believed to have the relevant first and second-hand information about the floods caused by Cuvelai River basin. The respondents who were sampled using the purposive/judgmental sampling method include Senior Officials from Oshakati, Ongwediva and Ondangwa town councils, officials from the Hydrology Department (Ministry of Agriculture, Oshana Region), and those from the Oshana Regional Council.

Judgmental sampling was complemented with a stratified sampling method, a method which involves dividing the population into non-overlapping subpopulations (Hoshaw-Woodard, 2001). A total of 136 people from various villages and those accommodated in temporary camps were selected. These were further grouped into three groups, A (those who have experienced the flood situation three times), B (those who have experienced the flood twice) and $\mathrm{C}$ (those who have experience the flood only once). Ten percent (10\%) of each group was used as a sample.

\subsection{Measures and Covariates}

The study relied on primary and secondary data that were collected by the researcher. It used questionnaires, individual in-depth interviews and focus group discussions as primary sources of information; and literature review as secondary sources.

In urban areas, primary data was obtained mainly from interviews conducted with key informants at the community level. Moreover, visual observations were used to determine the physical vulnerability of the selected communities. A structured questionnaire was administered to the villagers in addition to oral interviews, and on the spot assessment of the respondents' houses, to determine the extent of the damage made to properties. The questionnaire elicited information on the socio-economic characteristics of the respondents, their opinions towards how the government handles the situation, their coping mechanisms for floods, as well as their adaptation measures. The questionnaire also elicited information on how the disaster affected people's livelihood systems. Furthermore, the respondents were requested to give their perceptions of the causes of frequent rainstorms and flooding incidents, and to give their views as to how they understand climate changes issues. Some more data were collected on the characteristics of the respondents' houses and the neighborhood.

As part of primary data collection, the participants were: village headmen, councilors from constituencies in the Oshana Region, senior officials from the three town councils in Oshana i.e. (Oshakati, Ongwediva and Ondangwa), and officials from the Hydrology Department of the Ministry of Agriculture, Water and Forestry in the Oshana Region. Altogether the research gathered data from 130 villagers, who have experienced the actual floods. These villagers were sourced from 13 villages in the Oshana Region, namely: Onatshiku Tsha Laban, Iiviyongo, Uukwangula, Oniimwandi, Emono, Othingo, Ekuku, Oikango, Omusimboti, Ompundja, Oshipumbushomugongo, Eheke and Omagongati. A total of 13 clusters were formed, which were represented by people from the selected villages, who were selected based on the number of times that they had experienced floods.

Secondary data were sourced from literature on communities from the Oshana Region, particularly those related to flooding. In addition, relevant officials of the Oshana Regional Council were interviewed as part of the primary data collection process. Most of the officials that were interviewed were from villages within the region. An interview was also conducted with some members of the Directorate of Disaster Risk Management under the Office of the Prime Minister. A tape recorder was used to collect data through focus group discussions and indepth interviews.

\section{Results}

The study had four sub-objectives. The main objective was to find ways of mitigating the impacts of flooding in the Oshana region, focusing more on early warning system and strengthening the coping capacity for the region. The particular objectives were to analyse the process undertaken to mitigate the impacts of the flood in Oshana region, identify the challenges faced in the process of managing the flood situation in Oshana region, and suggest useful recommendations that could reduce the impacts of the Cuvelai River Basin/Oshana region flood. 


\subsection{Findings of the PAR Model}

The root causes of the disaster in Oshana region, as per respondents were a lack of resources, poverty, poor infrastructure and limited budget. The dynamic processes as reflected by the respondents were in the form of lack of training and skills about flood hazards and basic disaster risk management. In addition, the region is overcrowded, such that there is no space for new settlements, thus people in towns settled illegally in flood plain areas and the authority has sold land to investors that are situated in the water flow path of the Cuvelai basin. The community in the Oshana Region mostly have no choice but to live in unsafe conditions. Many people live in flood plain areas due to unavailability of land and overcrowding in the region. Moreover, most of the houses are constructed with poor materials such as wood or clay, which makes them more prone to destruction by flood water. Interestingly, it has been established that some people living in dangerous areas resist being moved to safe areas, given the fact that they want to be near their mahangu fields, grazing fields and water sources. All this can be attributed to low income levels and unemployment. Lack of preparedness for floods also contributes to a loss of properties and deaths. Figure 1 below presents the progression of vulnerability of the Oshana Region, based on the PAR Model.
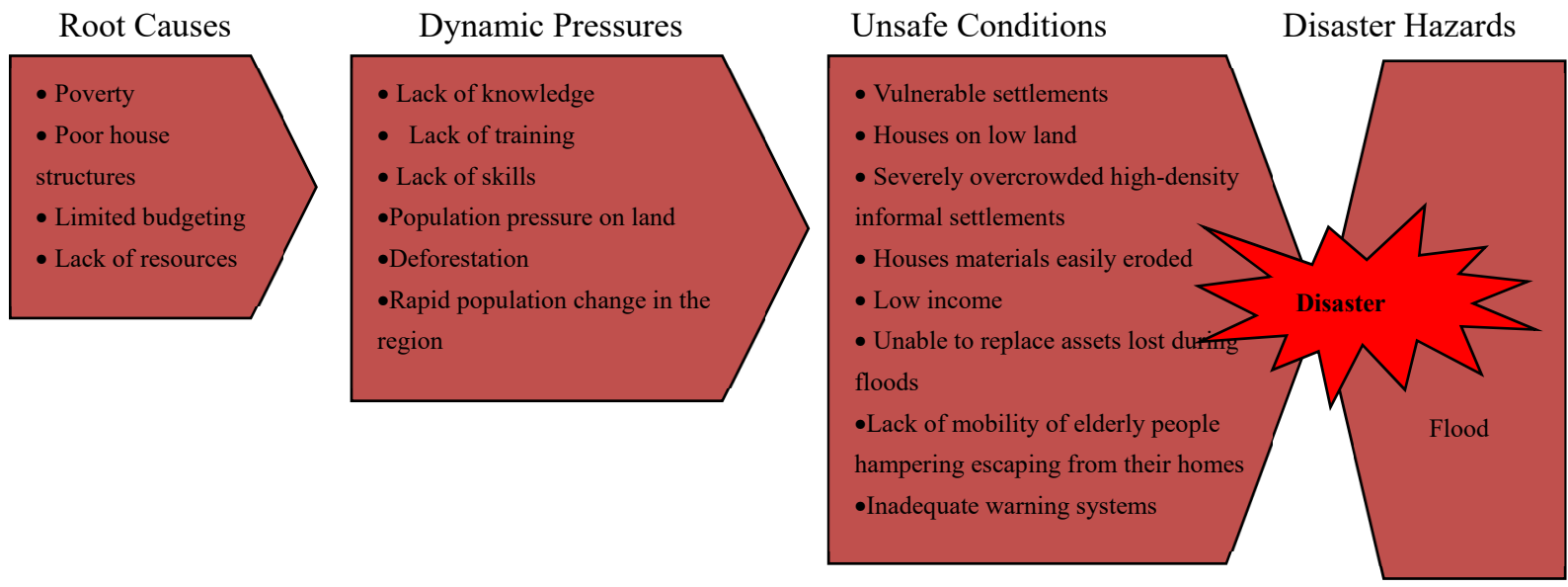

Figure 1. PAR Model illustrating Progression of vulnerability of Oshana Region. Source: Wisner et al. (2003), adopted by author (2012)

\subsection{Statistics and Data Analysis}

\subsubsection{Demographic Information}

The study findings revealed that the majority (70\%) of respondents were female (see Figure 2), particularly due to the fact that many males leave the area in search for employment in other regions. This ultimately contributes to community's vulnerability to floods, given the social and economic barriers that limit their coping capacity.

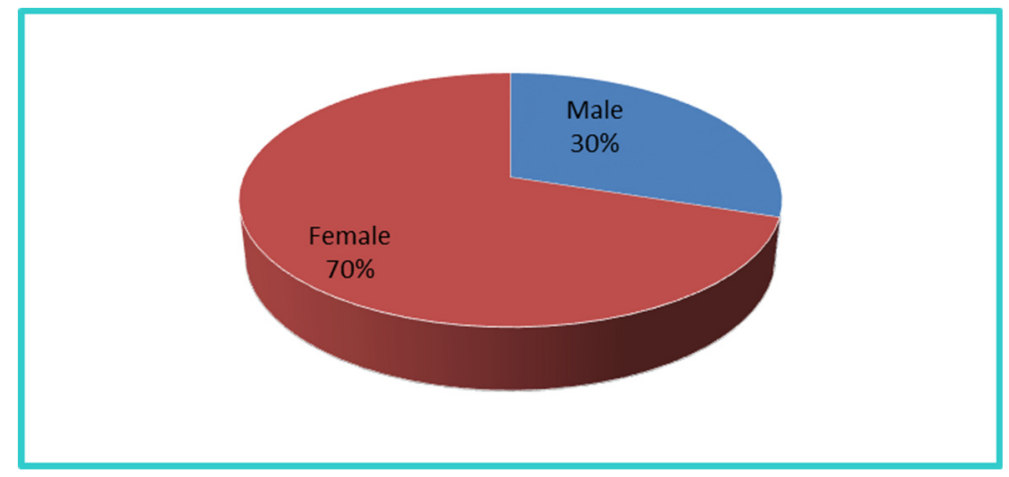

Figure 2. Respondents' gender

In terms of age, $21 \%$ of the respondents were aged between 20 and $30 ; 50 \%$ between 31 and 45 , while $28 \%$ were aged between 46 and 60 (Figure 3). Only one (1\%) percent represented respondents above the age of 60. 


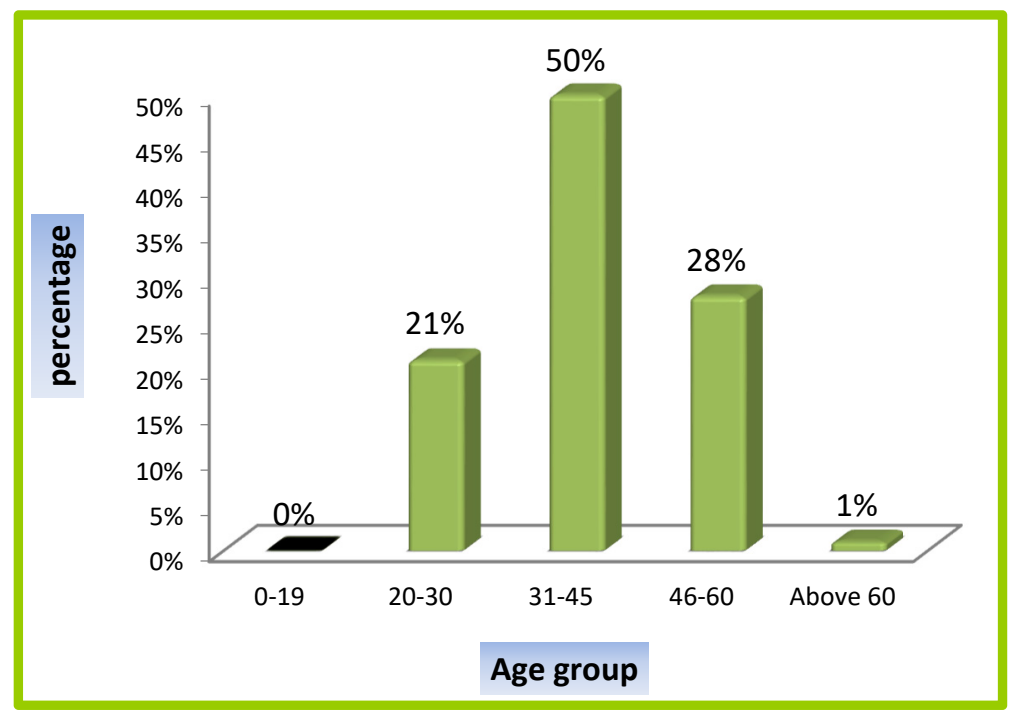

Figure 3. Percentage responses by age group

Of the total number of respondents, only $45 \%$ had completed primary school education, while $15 \%$ received the secondary education level (Figure 4 ). In addition, only $10 \%$ reached the university level, while $30 \%$ did not get any formal education.

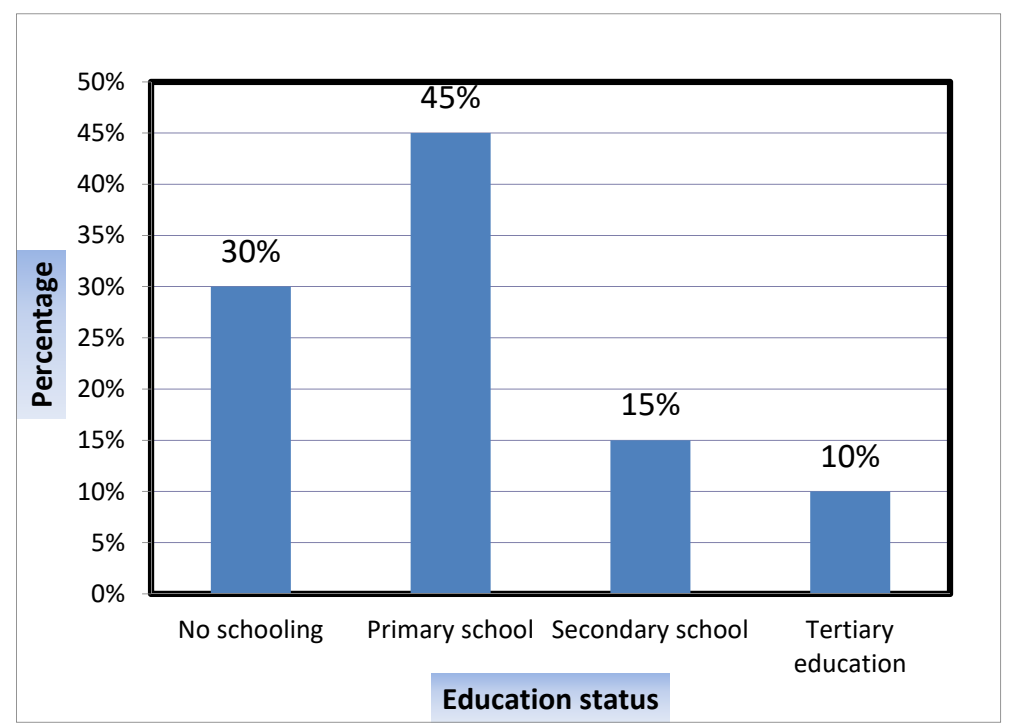

Figure 4. Respondents' education status

The study further revealed that most of the respondents $(60 \%)$ were unemployed during the time of the study (Figure 5). For those employed, 22\% were full-time employed; $11 \%$ were part-time workers, while $7 \%$ were selfemployed. It is not surprising that the employed people only formed $33 \%$ of the sampled population, since the majority of them only achieved low education level or received no education at all. Most of the unemployed respondents (32\%) live in informal dwellings made out of wooden structures, while the majority (12\%) of the fulltime employed respondents live in formal dwellings, constructed with bricks. In addition, a reasonable number $(5 \%)$ of the part-time employed respondents live in informal shack dwellings. 


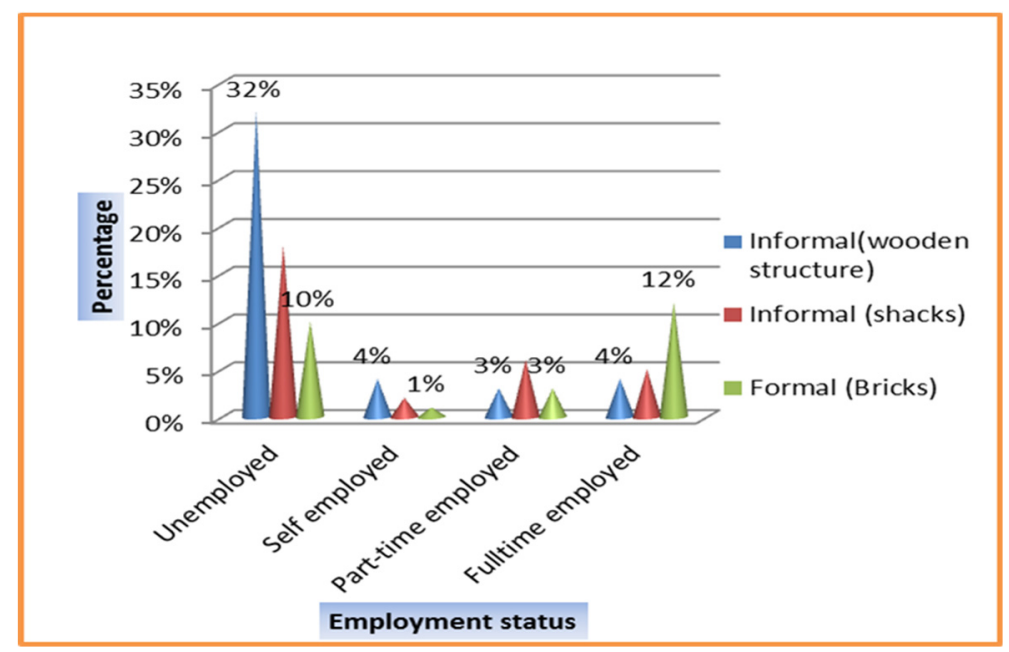

Figure 5. Employment status for the respondents

\subsubsection{Household Income}

The study revealed that most (45\%) households rely on a meager social grant, which is barely sufficient to feed the family members (Figure 6). While only $35 \%$ of households have employment as a source of income, $20 \%$ have no income at all. Therefore, when disaster strikes, those people are forced to relocate to high grounds, since they cannot afford to construct houses that are able to withstand the flood water. Consequently, the government makes efforts to relocate them, and provide temporary shelter along with basic needs.

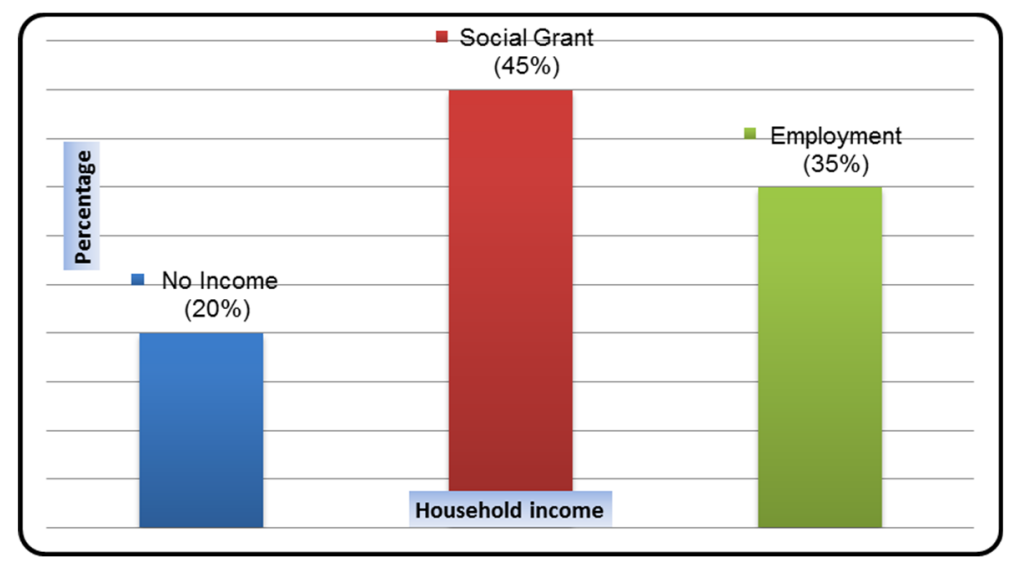

Figure 6. Source of household income

\subsubsection{Impact of Floods on Properties}

The study revealed that most of the people in communities within the Oshana Region predominantly depend on their mahangu fields as sources of food as provisions of social grants from the state are not guaranteed. Past flood events negatively affected $66 \%$ of mahangu fields, $48 \%$ of households, $12 \%$ of shops and $17 \%$ of other properties through destruction (Figure 7). Such a disaster left people in a predicament, such that they were left with nothing and had to face a very difficult economic situation for a while. Many were left in poverty, as they had no sources of income (their prime source of livelihood mahangu was destroyed). They eventually had to depend on government for immediate relief, such as to relocate them to higher grounds, provide temporary shelter and provide basic food. 


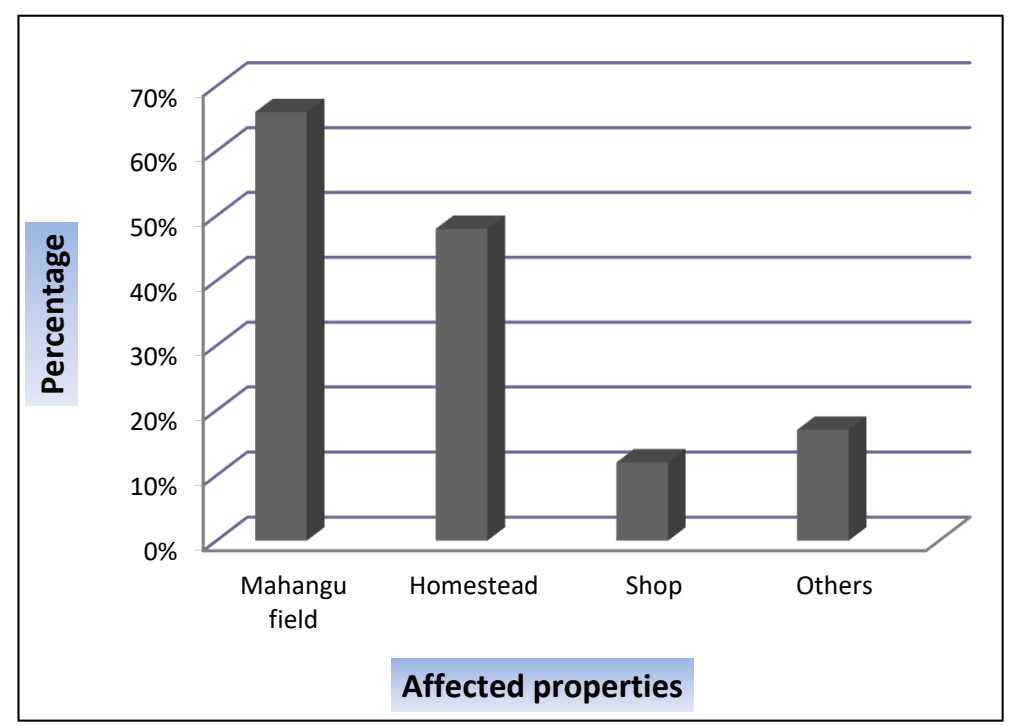

Figure 7. Percentage of affected properties

\subsubsection{Household Structures}

Figure 8 below indicates that the majority (57\%) of flood victims who participated in the research reside in informal settlement made of wooden structures in villages, followed by those living in shacks (29\%), and those living in brick houses (14\%). Sixty percent (60\%) of the respondents live in informal dwellings, are unemployed and only have primary school education, which placed them in a position of only being able to construct their houses with poor quality materials. These are unlike those people who live in formal dwellings, who were less impacted (14\%) in comparison.

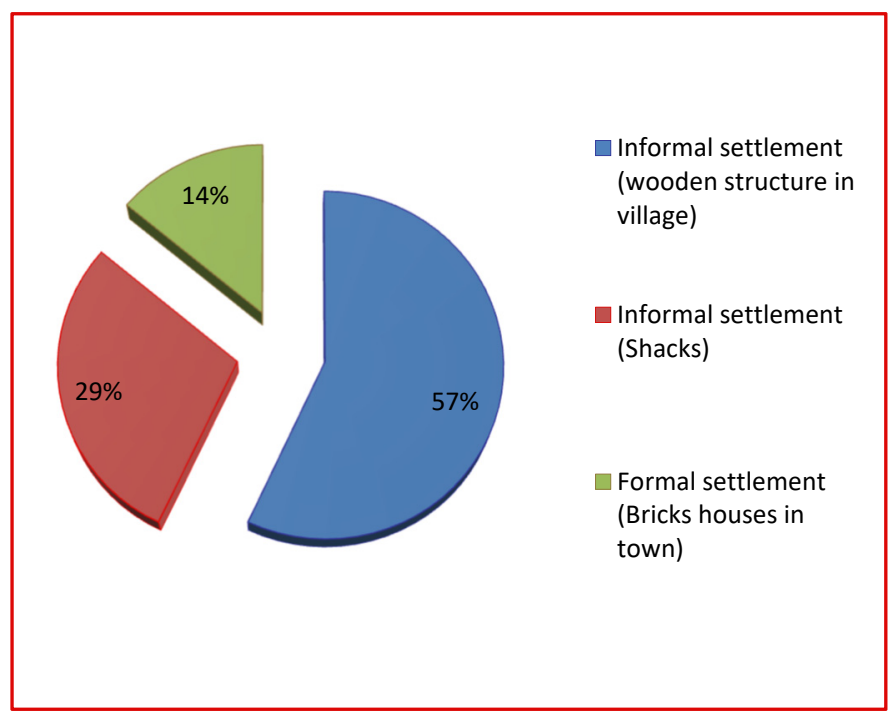

Figure 8. Household structures

\subsubsection{Flooding Experience}

Given the occurrence of the floods in different years, the flood victims were impacted differently. Figure 9 below indicates that $40 \%$ of the respondents were affected by floods more than twice, $35 \%$ were affected twice, while $25 \%$ were affected only once. Based on these statistics, most of the respondents were affected by flooding more than twice. 


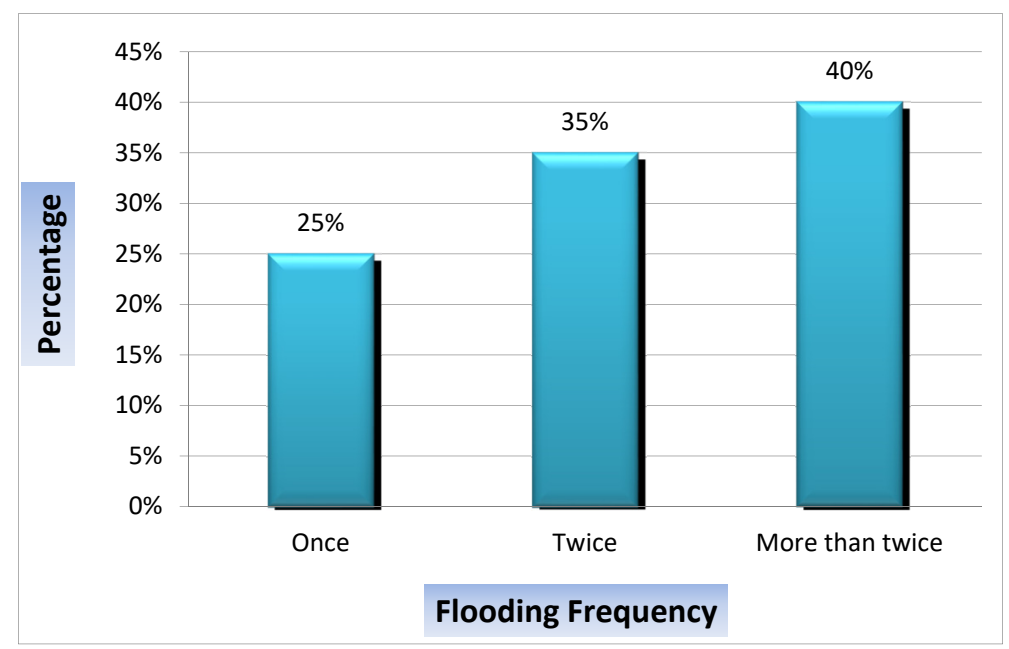

Figure 9. Flooding experiences

The flood event of 2011 was reported to be the worst in comparison to other flood events, primarily because of the extent of its impact, as indicated by $56 \%$ of the respondents (Figure 10). According to the participants, the 2011 flood event affected more people in comparison to the flood events of 2008, 2009 and 2010. This specific event was followed by that of 2009 , as confirmed by $27 \%$ of the respondents; while the 2008 and 2010 came the third and fourth, as indicated by $12 \%$ and $5 \%$ of the respondents respectively.

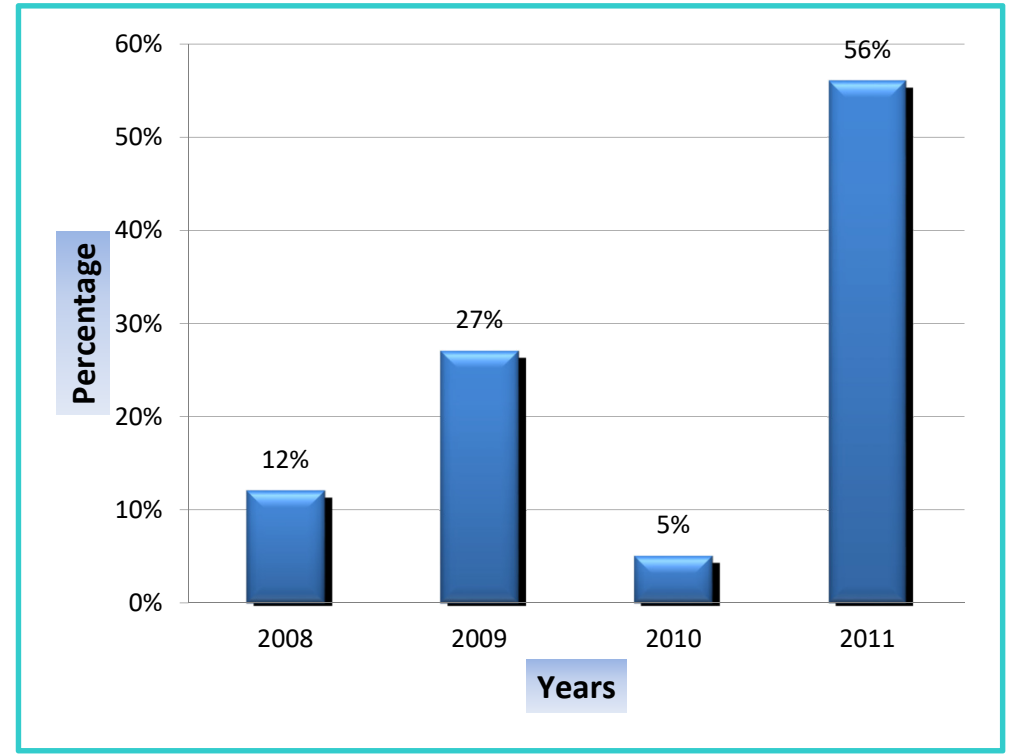

Figure 10. Severity of the past flood events

Figure 11 below gives an indication of the extent of the damage made by the 2011 floods. The respondents revealed that the 2011 flood impact was severe, as their only source of food and income i.e. mahangu production for consumption and selling was destroyed to a greater extent. An indication was made by $40 \%$ of the respondents that the floods that occurred that year destroyed crop fields, while $20 \%$ indicated that it destroyed houses. Thirty-five percent $(35 \%)$ indicated that it destroyed roads and other infrastructure, while 5\% indicated that the floods claimed many human lives. 


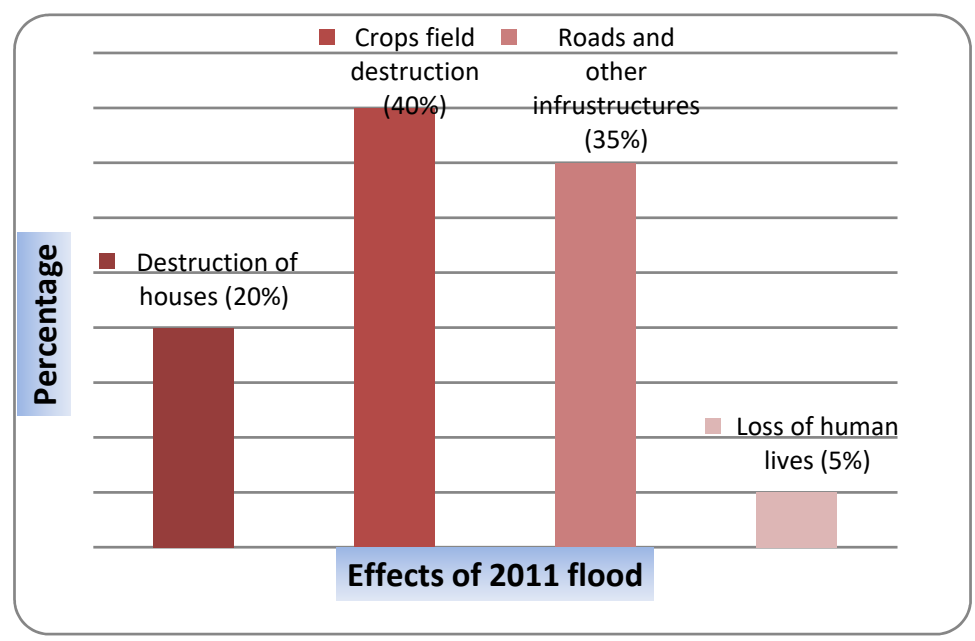

Figure 11. Effect of the 2011 flood event

The magnitude of the flood event of 2011 forced the community to be cut off from some services for a period of time. Figure 12 shows that $50 \%$ of the respondents were cut off from basic services such as health facilities, shops, schools and churches for 3 months; $41 \%$ for more than 3 months and $9 \%$ for 1 month.

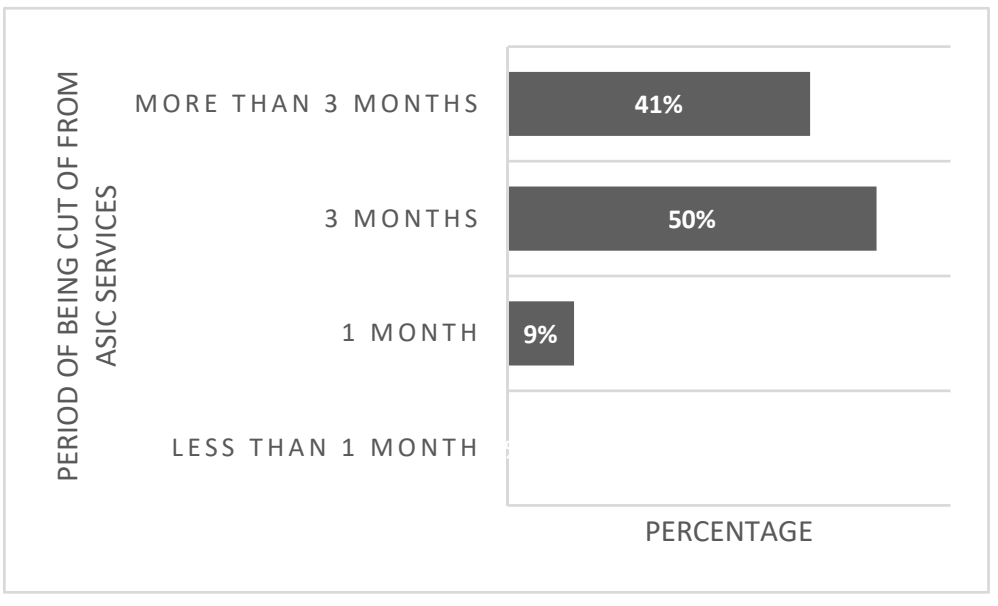

Figure 12. Respondents' period of being cut off from basic services during the 2011 flood event

\subsubsection{Sources of Information}

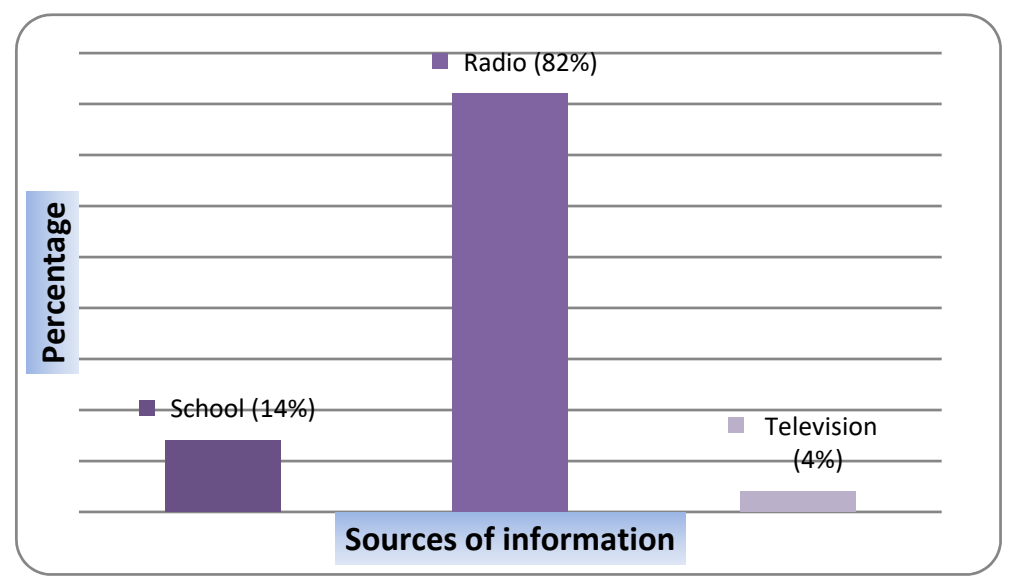

Figure 13. Sources of Information 
When it comes to obtaining climate-related information, different people use difference sources. As shown in Figure $13,82 \%$ of the respondents obtain information about the flood through radios, $14 \%$ get it from schools, while $4 \%$ get it from television.

\subsubsection{Awareness of Flood Related Issues}

Figure 14 below reveals that $65 \%$ of the respondents were not aware of flood reduction and prevention methods by the time of the research, compared to the $35 \%$ that were aware.

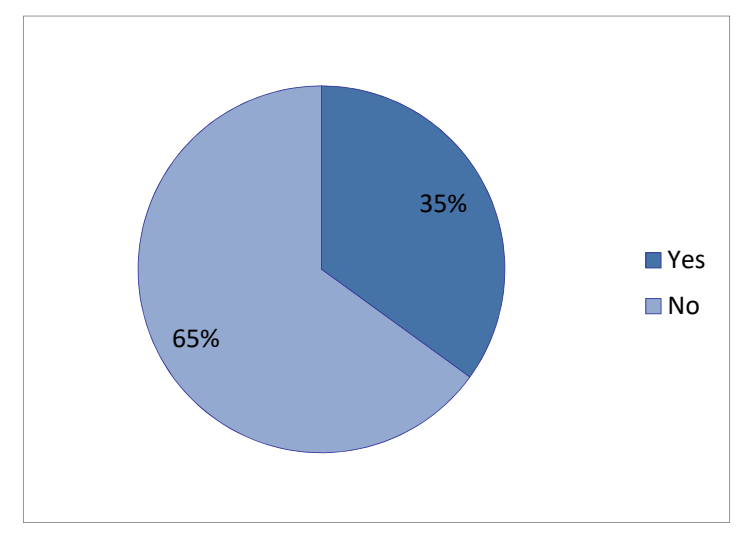

Figure 14. Awareness of Flood Related Issues

\section{Discussion}

The Progression of Safety is a reverse of the Pressure And Release model (PAR). The objective of the progression of safety is to reduce risks by addressing the root causes, dynamic pressures and unsafe conditions.

By addressing root causes of vulnerability, the vulnerable community would get more access to local resources and power structures as well as foster change in any exploitive political and or economic situation (Wisner et al., 2004, pp. 52-56). This would lead to the development of local institutions for the support of special groups in the community, availability of further education and training for the necessary skills to create sustainable livelihoods, support of local investments and the extension of markets.

\subsection{Addressing Root Causes}

Root causes are deep rooted set of factors that together form and maintain vulnerability: Oshana region has a high rate of poverty which is a result of low employment rate. Most of the community members solely depend on their mahangu and livestock farming for their income which is not constant. Poverty affects the majority of people in the region and the government can reverse it through job creation strategies. By addressing poverty, the region and the government will be conducting a risk reduction measure, which will eventually lead to disaster reduction. It is also a must that the government through local authorities and regional council build better infrastructures such as roads, bridges and communication systems. Poorly constructed infrastructures led to bridges being washed away during floods thereby cutting off many villages from basic services.

\subsection{Unsafe Conditions}

The majority of the population of Oshana region is staying in vulnerable settlements constructed with weak materials such as clay, wood, zinc and grass. The materials used to construct houses cannot withstand flood waters; as a result, the structures get washed away during flooding. To reduce vulnerability of the people, the government must employ engineering measures to enforce building codes in urban areas such as the Oshakati, Ongwediva and Ondangwa towns. Vulnerable persons in the villages within the region must be taught to construct strong structures in those flood prone areas. The government must find a way to subsidize the populations living in flood prone areas to construct their houses with materials that can withstand flood waters or relocate them to high grounds permanently.

\subsection{Dynamic Pressures}

Lack of information as a root cause to disaster can be addressed by ensuring that communities have free access to relevant and important information at all times. This could be achieved by radio announcements in all local languages, television broadcasts, pamphlets, schools, churches, council meetings, village headmen meetings and community gatherings. Thus the Oshana region needs to strengthen its distribution of information about flood 
hazards throughout the region to empower the population with knowledge about how to deal with the flood hazard and at the same time how to prevent being flooded. The other dynamic pressure of the Oshana region vulnerability is the movement of people into the region which causes overcrowding and puts pressure on land and result in people settling in vulnerable settlements. Thus there is an urgent need for the government of the Republic of Namibia to take development to other regions to avoid people migrating from those regions.

\subsection{Progression to Safety of Oshana Region}

The progression of safety for the Oshana Region addressed the root causes identified by the PAR model which included: limited access to safe land and information regarding possible flooding. This safety of the Oshana Region will be achieved through the following plan:

* The region needs to shift from response to risk reduction by capacitating its staff, councilors and the communities. The study revealed that the dynamic pressure of vulnerability to flooding in the region is due to lack of knowledge, skills and training about the flood hazard.

* The region must increase its funding of disaster risk reduction activities; as the respondents indicated that the region has limited budget when it comes to disaster risk management.

* The region must establish a disaster risk management center which is fully equipped and staffed; the study revealed that the region lacks resources which include human resources and disaster risk management structures.

* The Regional councilors needs to be empowered with disaster risk management knowledge in order for them to understand the importance of addressing the root causes of vulnerability to the affected communities, since they represent the communities at National council.

* Structures which are already located in flood prone areas should be engineered to withstand flood forces and designed with elevated floors to reduce damage by flood.

The findings revealed a low level of awareness of flood hazards in the high-risk areas (villages and informal settlements) in comparison with the low risk areas (towns) in the region. They were not aware of the nature of the flood-related risks they were exposed to and appeared to not be prepared for future floods but were more dependent on external aid. These were influenced by demographic variables such as gender and educational level.

\section{Limitations of the Study}

The study had challenges especially at data collection stage. Firstly, due to time constraints, the vast area covered by the Cuvelai River Basin and the recent devastating flood, it was not possible for the researcher to interview a great number of members of the community or assess the entire area affected.

Secondly, some people were traumatized by the recurrence of the flood and by the great loss that they have suffered and therefore could not give interviews.

Thirdly, frustration towards the government was mounting high and some persons especially the villagers assumed the researcher was a government representative. They expressed their views that they were tired of the government just interviewing them and not bringing about change.

\section{Ethical Considerations}

This study was undertaken after the University of the Free State (DIMTEC) approved the proposal. The research was conducted in line with the ethical research principles and the legal ethical requirements of the University.

The researcher had acquired a letter from the DIMTEC department, which explained the purpose of the study and established that the researcher was a student of the UFS. Throughout the study, the researcher ensured that all participants participated on a strictly voluntary basis with no form of coercion used. Confidentiality and trustworthy was maintained, and clearly communicating to the respondents together the reason for the research and where it will be used.

Fourthly, the language issue, $80 \%$ of the participants was conversant in Oshiwambo. The researcher had to translate the information received into English, and doing that without losing the meaning proved a challenge.

\section{Conflict of interests}

The authors declare that there is no conflict of interests regarding the publication of this paper.

\section{Reference}

Action Aid International. (2016). Climate change, urban flooding and the rights of the urban poor in Africa Key findings from six African cities. Retrieved from https://www.actionaid.org.uk/sites/default/files/doc _lib/urban_flooding_africa_report.pdf 
Afeku, K. (2005). Urbanization and Flooding in Accra, Ghana. Master's Thesis, Department of Geography, Miami University.

Amupadhi, T (2011). Floods shut schools in north. The Namibian Newspaper, 09 March 2011

Blaikie, P., Cannon, T., Davis, I., \& Wisner, B. (2004). At risk: Natural hazards, People's Vulnerability and disasters. Taylor \& Francis.

Dinnie, D. (2011). Flooding in SA: The Insurers position.

Dutta, D., \& Herath, S. (2005). Trend of floods in Asia and flood risk management with integrated river basin approach.

Food and Agriculture Organization. (2010). Lesotho; FAO in emergencies. Retrieved from http://www.fao.org/emergencies/countries/detail/en/c/168688

Hajat S, Ebi KL, Kovats S, Menne B, Edwards S, Haines A (2003). The human health consequences of flooding in Europe and the implications for public health: a review of the evidence Applied Environmental Science and Public Health 1(1): 13-21.

Kelman, I. 2001. "The Autumn 2000 Floods in England and Flood Management". Weather, vol. 56, no. 10 (October), pp. 346-348,353-360.

Langerhoven, G. V. (2008). Hydrological flood monitoring and warning system for upper cuvelai catchment. Oshakati: Guido van langer hoven.

Mucavele, F. G. (2011). The True Contribution of Agriculture to the Economic Development of Mozambique. Food Agriculture and Natural Resources Policy Analysis Network. Maputo, Mozambique.

Namwater. (2009). News bulletin (Vol. 6). Namibia.

National Planning Commission. (2009). March 2009 flood. Windhoek: National Planning Commission.

Office of the Prime Minister: Directorate Disaster Management. (2009). Report on the 2009 Flood Disaster Response. Windhoek.

Oshana Regional Council. (2011). Disaster Risk Management. Retrieved from http://www.oshanarc.com/disasterrisk-management/

Smith, K and Warders (1998) Floods: physical processes and human impacts. Chichester and New York: John Wiley

Smith, W. (2006). Understanding the complexities of informal settlements: Insights from Cape Town. In M. Huchzermeyer \& A. Karam (Eds.), Informal Settlements: A perpetual challenge? UCT press, Cape Town.

Spiazzi, A. (2011). Namibia flood situation. Windhoek: Agnese Spiazzi.

Thomas, D. (2005). ADAPTIVE: Adaptations to climate change amongst natural resource-dependent societies in the developing world: Across the Southern African climate gradient. Tyndall Centre for Climate Change Research Technical Report 3

U.N Office for Coordination of Humanitarian Affairs (2009). Floods and Cyclones Situation Report no.2 (pdf).

USAID. (2007). Southern Africa Humanitarian Assistance in Review 2007-2008. Retrieved from https://www.usaid.gov/sites/default/files/documents/1866/southern_africa_overview_2007-2008.pdf

Wareham, M. (2000). Human Rights Watch article: Landmines in Mozambique: After the Floods. Retrieved from http://www.hrw.org/legacy/backgrounder/arms/mines-moz.htm. Accessed on: April 10, 2010

Wisner, B., Blaikie, P., Cannon, T., Davis, I. (2003). At Risk: Natural Hazards, People's vulnerability, and Disasters.: Routledge.

Zaman, M. Q. (1991). The displaced poor and resettlement policies in Bangladesh. Disasters, 15, 117-25.

\section{Copyrights}

Copyright for this article is retained by the author(s), with first publication rights granted to the journal.

This is an open-access article distributed under the terms and conditions of the Creative Commons Attribution license (http://creativecommons.org/licenses/by/4.0/). 